\title{
Extra teeth and dental anomalies in the crested porcupine Hystrix cristata, from Sicily
}

\author{
Francesco M. ANGELICI and Luca LUISELLI
}

\begin{abstract}
Angelici F. M. and Luiselli L. 1999. Extra teeth and dental anomalies in the crested porcupine Hystrix cristata, from Sicily. Acta Theriologica 44: 219-223.

We examined 181 skulls of crested porcupine Hystrix cristata Linnaeus, 1758 from Sicily, mainland Italy, and from several African countries. Two skulls, both from Sicily, had anomalous dentition. One skull exhibited a case of supernumerary dentition, whereas the other one showed a dental malformation with numerary teeth reduction. The type of anomaly was determined in each skull examined and some hypotheses for explaining these anomalies were presented.
\end{abstract}

F.I.Z.V., Mammal Section, via Cleonia 30, I-00152 Roma, Italy (FMA) and F.I.Z.V., Herpetological Section, via Olona 7, I-00198 Roma, Italy (LL)

Key words: Hystrix cristata, dental anomaly, Sicily, Italy

The occurrence of extra teeth has been reported for nearly all orders of mammals (cf Wolsan 1984). Wolsan's (1983, 1984) hypotheses to explain supernumerary dentition are: (i) an effect of additional creation and development of tooth germ due to influences of genes which are still present in the species' gene pool but occurred much more frequently in the gene pools of the ancestral species, and (ii) an effect of supernumerary tooth germ development that originated as a result of complete splitting of a tooth germ, inherited or due to a mutation or disturbance or change in the genetic control of tooth development. Several findings of extra teeth phenomena have been recorded in rodents. Normally, these records refer to supernumerary molars (eg Johnson 1952, Sheppe 1964).

There are many records of tooth anomalies in mammals, eg Marsupialia (Archer 1975, Miller 1977), Lagomorpha (Suchentrunk et al. 1992); Rodentia (Barasa et al. 1992), and Carnivora (Hancox 1988, Kompanje and De Vries 1992). In general, nearly all the mammal dental anomalies (including supernumerary dentition) may depend on genetic, nutritional, physiological, inflammatory or proximate extrinsic factors (cf Colyer 1936, Archer 1975).

In this paper we report, for the first time, a case of supernumerary dentition, and a case of numerary reduction and dental malformation in free-ranging crested porcupines Hystrix cristata Linnaeus, 1758 from Sicily (Mediterranean Sea, Italy). In Europe this species occurs exclusively in mainland Italy and Sicily (cf Angelici 1991, Amori and Angelici 1992), whereas in Africa it is distributed from Mediterranean 
coasts to central Zaire and northern Tanzania (cf Haltenorth and Diller 1980). The dental formula of genus Hystrix is: i $1 / 1$; c $0 / 0 ;$ p $1 / 1 ; \mathrm{m} 3 / 3=20$.

We examined a total of 181 skulls of Hystrix cristata: 19 skulls from Sicily (12 skulls of adults, 7 of sub-adults), 60 from mainland Italy (41 adults and 19 sub-adults), and 102 from Africa (79 adults and 23 sub-adults), housed in the museums of Calci, Cesena, Firenze, Frankfurt, Geneva, London, Madrid, Nazzano, New York, Ostellato, Palermo, Paris, Pisa, Roma, Terrasini, Trieste, Udine, Venezia, Washington, Wien, and in several private collections. The relatively low number of examined specimens is due to the scarcity of $H$. cristata in skull collections of natural history museums. Moreover, skulls are often in bad condition, with lacking parts and without indication of the exact locality of origin.

Our analysis revealed two skulls from Sicily that had anomalous dentition, whereas those from mainland Italy and Africa appeared normal. Skull no. 69 from the collection of the Natural History Museum of Friuli, Udine (Fig. 1) was of an adult specimen (with both premolars and all molars completely erupted) of unknown sex, found dead in the vicinity of Siracusa (Sicily), in October 1979. The skull has a small-sized and still uncompletely erupted fourth molar in the upper jaw, on both sides. The dentition of the lower jaw is normal.

Skull no. 21 B from the collection R. Basso (c/o Po Delta Natural History Museum, Ostellato, Ferrara) (Fig. 2) was of an adult specimen. Although the dentition is highly altered, the premolars and the third upper and lower molars, when present, are completely erupted. It was a male labelled "Sicily 1972". In the upper jaw on the left side, there is only the third molar, whereas anterior to it an anomalous (very low-deep) tooth-socket and a large depression (prior to the above

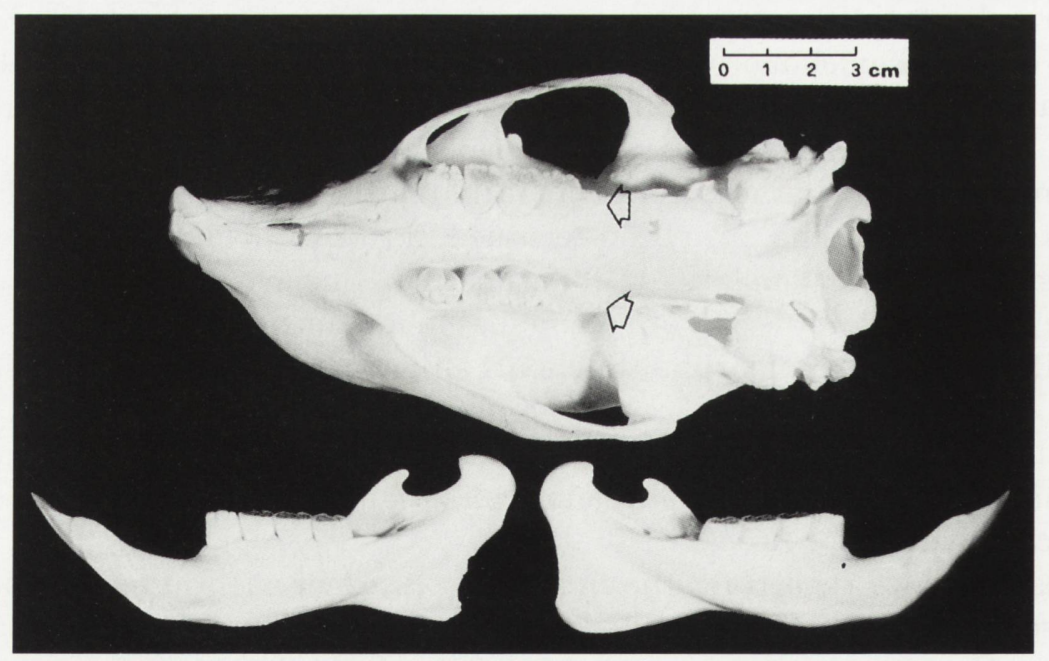

Fig. 1. Skull of an adult Hystrix cristata showing extra-teeth distal to the third molars. Skull no. 69 from the collection of the Natural History Museum of Friuli, Udine. 
socket) are also present. On the right side, the premolar is irregularly grown, with a moderately worn crown directed posteriorly. Moreover, the first and second molars are very small with irregular crowns and shortened roots, and the third molar is characterized by a rounded and worn crown. The incisors are apparently normal on both sides.

The lower jaw is also characterized by remarkable anomalies. On the left side, the premolar and the three molars (the first one is actually lacking but was once present) have irregularly oriented sockets and, as a consequence, the orientation of the premolar is toward the buccal side of the mandible. The second and third molars are oriented toward the lingual side of the mandible. The first molar, which was probably very small-sized, would have had a triangular crown and cuneiform root (at least on the basis of socket examination). Moreover, the left premolar has a very high crown, practically without any sign of wear (Fig. 3). The right side of the mandible has three molars, but the premolar is lacking. The first molar (and its socket) is very small and apparently vestigial, and the premolar socket is completely lacking. As a result, the diastema is very long (Fig. 2). The right incisor is lacking and the whole right dentary is relatively thin due to the lack of the continually growing root of the incisor. The left incisor is quite regular.

In general, the frequency of dental anomalies in porcupines from Sicily is not significantly different from that observed in porcupines from mainland Italy (Fisher exact test, $p=0.056$ ), but it was significantly higher than that observed in both mainland Italy and Africa pooled together (Fisher exact test, $p=0.01$ ).

A main point emerging from our analysis is that remarkable dental anomalies occurred only in $H$. cristata from Sicily. Could this be an effect of insularity? Due

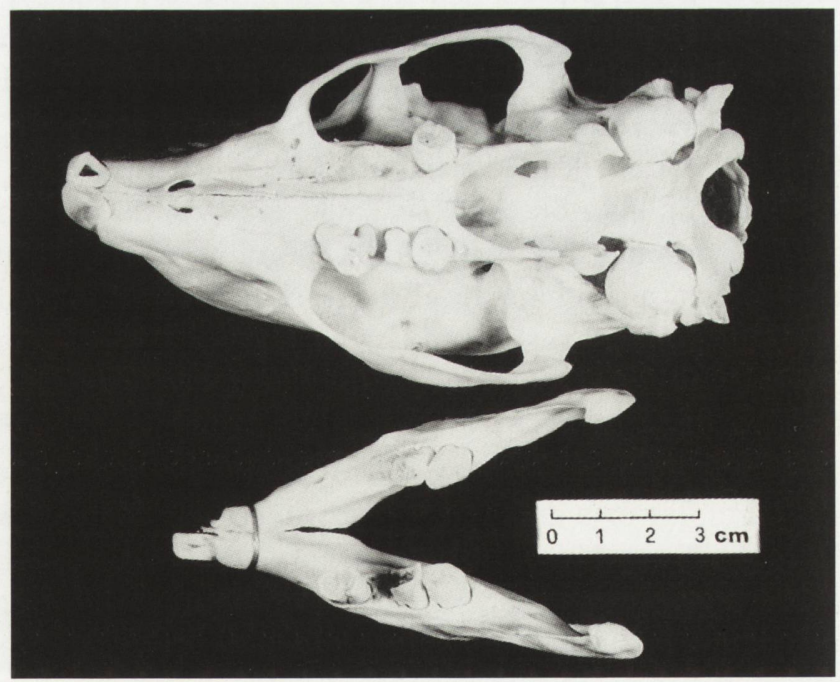

Fig. 2. Skull of an adult male $H$. cristata with several dental anomalies. Skull no. 21 B, collection R. Basso, c/o Po Delta Natural History Museum, Ostellato (FE). 


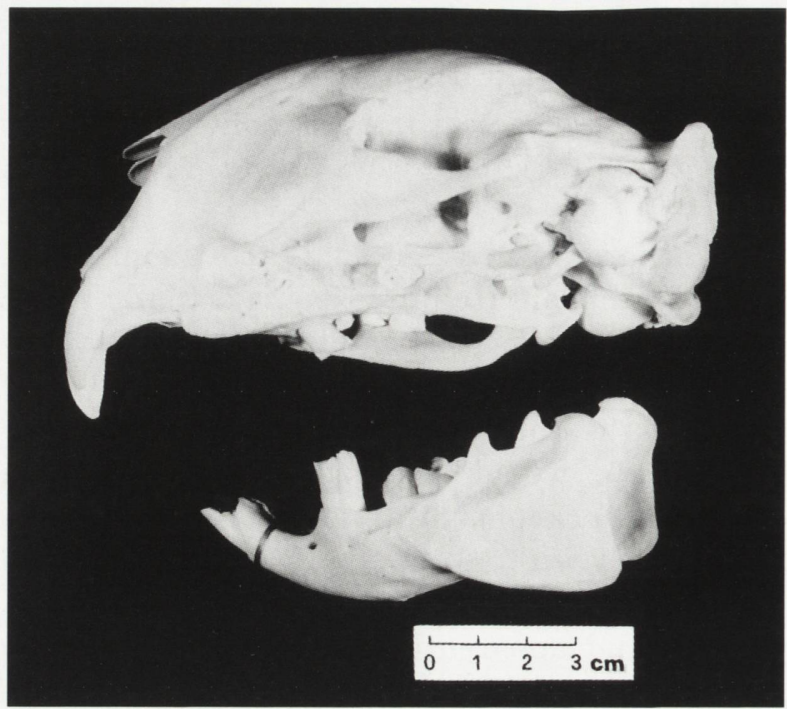

Fig. 3. The same skull as in Fig. 2, lateral view.

to very small sample, we do not think so, especially because we do not know whether the Sicilian porcupine population is originally autochtonous (as seems probable, cf Amori and Angelici 1992, Angelici and Amori, in press) or introduced by man, and therefore any potential founder effect cannot be readily demonstrated.

The supernumerary dentition recorded in the first skull described here is possibly due to genetical reasons (sensu hypothesis (ii) in Wolsan 1984), and has also been observed in the Asiatic congeneric H. indica (F. M. Angelici, unpubl. data). Based on the examination of the tooth wear, we suggest that this kind of alteration did not produce masticatory problems to the animal.

With regard to the other skull described here, we could also stress that the wide and peculiar anomalies observed (ie lack, size reduction and deformity of teeth) have genetical reasons (cf Colyer 1936). Due to these anomalies, the animal probably had masticatory problems, as indicated by both the strange orientation and the different amount of abrasion on the premolar and molar crowns (Fig. 3). It is also probable that external proximate factors contributed to the altered dentition. This seems to be true for the first left molar of the lower jaw, which had a low deep root and was consequently lost during the life possibly due to constriction caused by the second molar or a dento-alveolar infection degenerated in an abscess (cf Colyer 1936). Hancox (1980) presents some records of this kind in the Eurasian badger Meles meles from both Britain and continental Europe. The same could have occurred to the vestigial second left molar of the upper jaw, which is lacking (as evidenced by its anomalous socket), whereas the contiguous concavity seems to be due to the pressure caused by the corresponding enormously high premolar of the lower jaw. However, we cannot exclude that initially in this 
position there had been or more precocious teeth (anomalous, smaller sized and with low deep roots), which here lost later on and formed cicatrized tissue. In conclusion, it is probable that the dentition status of this latter skull could have influenced the life and fitness of this specimen, despite the fact that it was probably an aged individual.

Acknowledgements: We are grateful to L. Lapini (Natural History Museum of Friuli, Udine) and R. Basso (Po Delta Natural History Museum, Ostellato, FE ) for having lent us the two skulls studied in the present paper. Moreover, we are especially indebted to G. Amori (Chairmain IUCN Rodent Specialist Group, Rome) for having critically commented on an earlier draft of the manuscript, and to D. Capizzi (Rome) for having produced the photos and for a lot of collaboration. D. P. O' Patrick (Dublin) improved the English on an earlier draft of this manuscript.

\section{References}

Amori G. and Angelici F. M. 1992. Note on the status of the crested porcupine Hystrix cristata in Italy. Lutra 35: 44-50.

Angelici F. M. 1991. L'istrice in Italia. [In: Ambiente Italia 1991. G. Melandri and G. Conte, eds]. Lega per L'Ambiente, Mondadori, Milano: 321-324.

Angelici F. M. and Amori G. Distribution of the Crested porcupine (Hystrix cristata L., 1758) in Italy and Sicily. Bollettino del Museo regionale di Scienze naturali, Torino. (in press)

Archer M. 1975. Abnormal dental development and its significance in dasyurids and other marsupials. Memories of the Queensland Museum 17: 251-265.

Barasa A., Gallo Orsi U. and Durio P. 1992. Anomalous tooth growth in an alpine marmot (Marmota marmota). [In: Proceedings of First International Symposium on Alpine Marmot (Marmota marmota) and on genus Marmota (Saint Vincent, Aosta, Italy, October 28-30, 1991). B. Bassano, P. Durio, U. Gallo Orsi and E. Macchi, eds]. Università di Torino, Dipartimento di Produzioni Animali, Epidemiologia ed Ecologia, Torino: 197-198.

Colyer F. 1936. Variations and diseases of the teeth of animals. Bale \& Danielson, London: 1-750.

Haltenorth T. and Diller H. 1980. A field guide to the mammals of Africa including Madagascar. Collins, London: 1-400.

Hancox M. 1980. Parasites and infectious diseases of the Eurasian badger (Meles meles L.): a review. Mammal Review 10: 151-162.

Hancox M. 1988. Dental anomalies in the Eurasian badger. Journal of Zoology, London 216: 606-608.

Johnson D. H. 1952. The occurrence and significance of extra molar teeth in rodents. Journal of Mammalogy 33: 70-72.

Kompanje E. J. O. and De Vries G. Th. 1992. An almost toothless badger Meles meles. Lutra 35: 40-43.

Miller W. A. 1977. Extreme tooth loss in a specimen of Isoodon macrourus (Peramelidae: Marsupialia). Australian Wildlife Research 4: 229-232.

Sheppe W. 1964. Supernumerary teeth in the deer mouse, Peromyscus. Zeitschrift für Säugetierkunde 29: 33-36.

Suchentrunk F., Markowski J., Janiszewski T. and Hartl G. B. 1992. Dental and cranial anomalies in Austrian and Polish brown hare Lepus europaeus populations. Acta Theriologica 37: 241-257.

Wolsan M. 1983. Ancestral characters in the dentition of the weasel Mustela nivalis L. (Carnivora, Mustelidae). Annales Zoologici Fennici 20: 47-51.

Wolsan M. 1984. The origin of extra teeth in mammals. Acta Theriologica 29: 128-133.

Received 24 October 1997, accepted 5 Novemebr 1998. 